\title{
TECHNIQUE
}

\section{Closure of Blalock-Taussig shunts using a new detachable coil device}

Andrew J P Tometzki, Alan B Houston, Andrew N Redington, Michael L Rigby, Dirke A Redel, Neil Wilson

\begin{abstract}
Two children underwent interventional closure of a modified Blalock-Taussig shunt using a new detachable coil system (Duct-Occlud). This procedure has advantages over currently available materials to occlude these and other communications between the systemic and pulmonary circulations.
\end{abstract}

(Br Heart f 1995;73:383-384)

Keywords: transcatheter occlusion; Blalock-Taussig shunts; interventional closure

Aortopulmonary collaterals and unwanted surgically constructed systemic to pulmonary shunts are attractive lesions for transcatheter occlusion. Several methods and devices have been described. Occlusion techniques using coils in particular have a significant hazard of unwanted embolisation during the procedure to the pulmonary and systemic circulations. We describe the use of a new spiral diabolo coil device (Duct-Occlud PFM, Bonn) for the closure of such lesions which has the benefit of being detachable, allowing manipulation before release when appropriately positioned. ${ }^{1}$
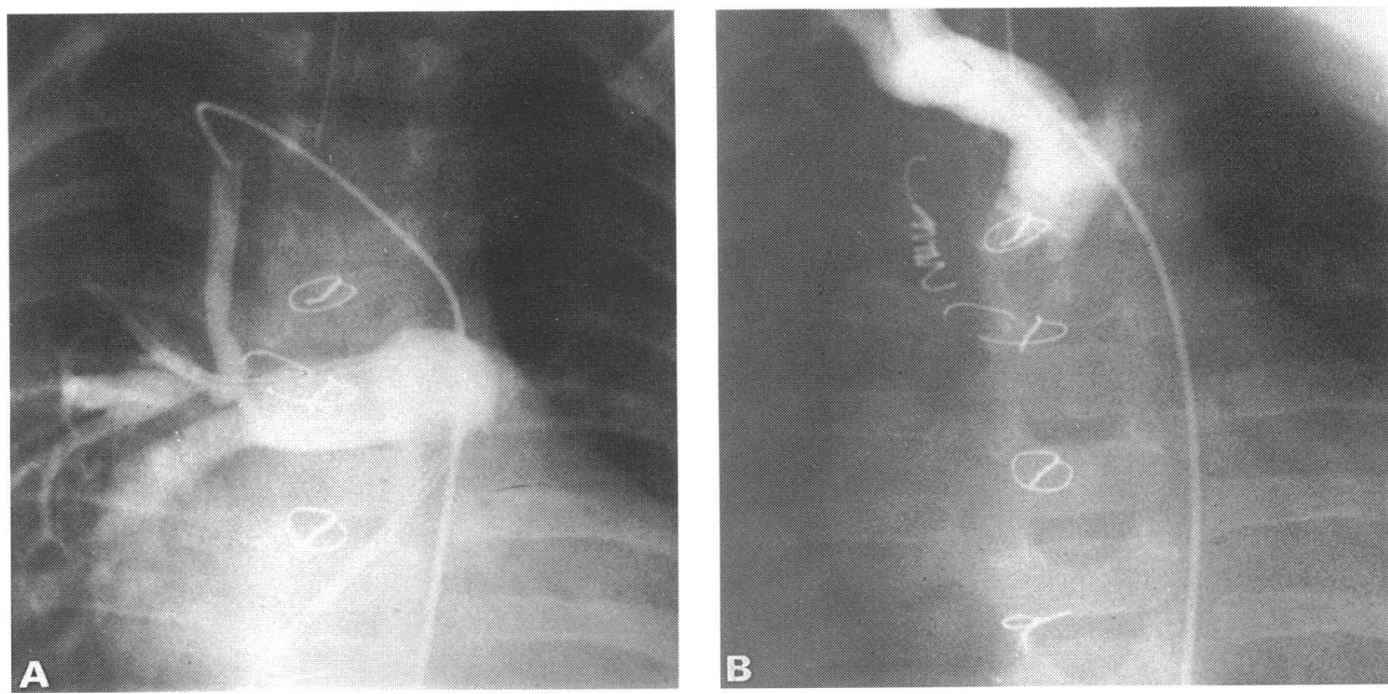

Figure 1 (A) Angiogram of the modified right Blalock-Taussig shunt demonstrating patency. (B) Angiogram after implantation of the diabolo coil device showing total occlusion of the shunt.

\section{Case reports}

PATIENT 1

A 17 month old boy initially presented with critical pulmonary valve stenosis on day 1 of life. He underwent open pulmonary valvotomy on day 2 but required a modified right polytetrafluoroethylene (Gore-tex) $5 \mathrm{~mm}$ Blalock-Taussig shunt within $24 \mathrm{~h}$. At 15 months of age he had made good progress and Doppler echocardiography demonstrated a gradient of only $9 \mathrm{~mm} \mathrm{Hg}$ across the right ventricular outflow tract. A soft persistent continuous murmur was present at the right infraclavicular area. Cardiac catheterisation with temporary balloon occlusion of the shunt was performed during which a minimal decrease in arterial oxygen saturation ( $96 \%$ to $92 \%$ ) was observed.

A further cardiac catheterisation was performed under general anaesthesia 2 months later when he weighed $9 \cdot 4 \mathrm{~kg}$. Retrograde arterial angiography showed the shunt to be patent with mild mid-segment narrowing (fig 1A). A 4 FG delivery catheter was placed in the shunt via the left femoral artery over a previously sited 0.021 inch exchange wire. A detachable spiral coil (Duct-Occlud) (maximum diameter of $5 \mathrm{~mm}$ ) was deployed into the shunt without incident. Distal flow occlusion was accomplished with a $10 \mathrm{~mm}$ balloon

Royal Hospital for Sick Children, Glasgow

A J P Tometzki A B Houston N Wilson

Royal Brompton Hospital, London A N Redington M L Rigby

University of Bonn, Bonn, Germany D A Redel

Correspondence to: Dr N Wilson, Departmen of Cardiology, Royal Hospital for Sick Children Yorkhill NHS Trust

Accepted for publication 13 October 1994 


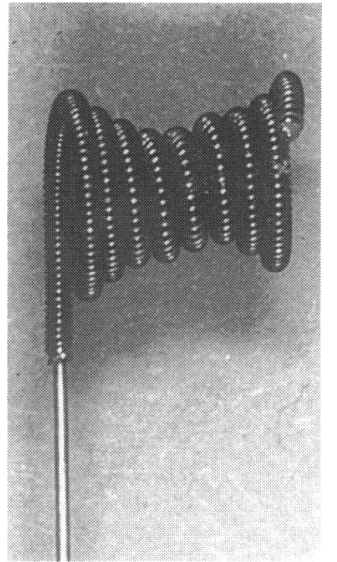

Figure 2 Duct-Occlud device. Diabolo shape evident on configuration of the device as it is pushed off the delivery wire. placed in the right pulmonary artery and inflated during release of the coil. Repeat angiography showed total occlusion of the shunt some minutes after successful implantation (fig 1B). Colour flow mapping Doppler echocardiography performed the next day confirmed this finding. The infant went home within $24 \mathrm{~h}$ of the procedure without complication.

\section{PATIENT 2}

A 41 month old boy presented with critical pulmonary valve stenosis on the first day of life. He underwent balloon dilatation of the valve at 3 days of age after which cyanosis remained with intermittent and profound episodes of desaturation. Cyanosis continued despite complete resolution of his valve gradient because of poor right ventricular compliance and a $5 \mathrm{~mm}$ modified left polytetrafluoroethylene (Gore-tex) Blalock-Taussig shunt was required on day 22 . Follow up 3 years later showed a minimal right ventricular outflow gradient of $20 \mathrm{~mm} \mathrm{Hg}$ with a clinically evident patent shunt.

At the age of 3 years 7 months (weighing $13 \mathrm{~kg}$ ) a $4 \mathrm{FG}$ delivery sheath was placed in the left femoral artery and retrograde arterial angiography was performed. This confirmed a patent shunt with a minor degree of stenosis towards the pulmonary artery end. The minimum diameter of the shunt was $4 \mathrm{~mm}$. A spiral coil (pfm Duct-Occlud) was deployed into the shunt. Initially the distal windings were placed towards the pulmonary side of the shunt, the coil was then withdrawn to the site of the stenosis, and the remainder of the windings delivered. Repeat angiography 15 min after insertion confirmed complete occlusion of the shunt. The patient made an uneventful recovery.

\section{Discussion}

Closure of unwanted Blalock-Taussig shunts and other aortopulmonary collaterals via a transcatheter route has been reported by several authors. ${ }^{1-5}$ In a review by Burrows et $a l^{2}$ of transcatheter occlusion of Blalock-Taussig shunts in 17 patients, using a number of methods including coil implantation, detachable balloons, and Rashkind devices, closure was successful in 14 cases, however, there was a high incidence (five cases) of embolisation of the device into the pulmonary circulation. Distal flow arrest by placement of the balloon catheter in this series seemed to reduce the chance of embolisation.

A new device (pfm Duct-Occlud) for transcatheter occlusion of aortopulmonary shunts including persistent arterial ducts has recently been described. ${ }^{1}$ This device has a number of important advantages. The delivery catheter is small (4 FG) compared with that of the Rashkind umbrella delivery system which requires a much larger sheath. Additionally, the device has a larger diameter at its distal and proximal ends with a narrower central portion and on deployment constitutes a diabolo shape (fig 2). The coil has the ability to be placed, manipulated, and fully retracted back into the delivery catheter without wastage if satisfactory positioning is not immediately obtained. Furthermore, even if the device is fully constituted beyond the delivery catheter retrieval is still possible. The chances of embolisation are therefore likely to be reduced and the need for distal flow occlusion with balloon catheter placement suggested by some authors and as used in the first case may be unnecessary..$^{2-4}$

We conclude that this diabolo device ( $\mathrm{pfm}$ Duct-Occlud) is a suitable alternative for the occlusion of Blalock-Taussig shunts. Its small delivery catheter of only 4 FG facilitates its use in children weighing less than $10 \mathrm{~kg}$. Preliminary experience suggests that this device may have wider uses in the field of interventional vascular occlusion.

1 Le TP, Ness MB, Redel DA, Weinzheimer HR. A new transcatheter occlusion technique with retrievable, double-disk shaped coils-first clinical results in occlusion of patent ductus arteriosus. Cardiology in the young 1993;3(suppl 1):38

2 Burrows PE, Edwards TC, Benson LN. Transcatheter occlusion of Blalock-Taussig shunts: technical options fournal of Vascular and Interventional Radiology 1993;4: $673-80$.

3 Houde C, Zahn EM, Benson LN. Transcatheter closure of Blalock-Taussig shunts with a modified Rashkind umbrella delivery system. Br Heart f 1993;69:56-8.

4 Rothman A, Tong AD. Percutaneous coil embolization of superfluous vascular connections in patients with consuperfluous vascular connections in patients with

5 Redington AN, Rigby ML. Novel uses of the Rashkind ductal umbrella in adults and children with congenital heart disease. Br Heart $\mathcal{f}$ 1993;69:47-51. 